\title{
Stimulation of acetylcholine receptors impairs host defence during pneumococcal pneumonia
}

\author{
I.A.J. Giebelen*\#, M. Leendertse*,\# , S. Florquin ${ }^{*}$ and T. van der Poll*\#
}

ABSTRACT: The cholinergic nervous system can inhibit the systemic inflammation accompanying sepsis by virtue of a specific action of acetylcholine on $\alpha 7$ cholinergic receptors. The current authors sought to determine the effect of nicotine, an $\alpha 7$ cholinergic receptor agonist, on the host response to pneumonia caused by Streptococcus pneumoniae.

Mice were intranasally infected with $S$. pneumoniae and treated with nicotine or saline intraperitoneally using a treatment schedule shown to improve host defence against abdominal sepsis.

Nicotine treatment was associated with a transiently enhanced growth of $\mathrm{S}$. pneumoniae, as indicated by higher bacterial loads in both lungs and blood at $24 \mathrm{~h}$ after infection. At $48 \mathrm{~h}$ after infection, bacterial burdens had increased in both treatment groups and differences were no longer present. Remarkably, mice treated with nicotine showed enhanced lung inflammation at $24 \mathrm{~h}$ after infection. Moreover, both lung and plasma concentrations of the pro-inflammatory cytokines tumour necrosis factor- $\alpha$ and interferon- $\gamma$ were higher in nicotine-treated animals at this time-point. Additional studies examining the effect of nicotine on the immediate (4-h) inflammatory response to $S$. pneumoniae did not reveal an anti-inflammatory effect of nicotine either.

The present data suggest that nicotine transiently impairs host defence in pneumococcal pneumonia.

\section{KEYWORDS: Airway infection, airway inflammation, animal, chemokines, cytokines}

$\mathrm{T}$ he cholinergic nervous system can regulate inflammation via its principal neurotransmitter, acetylcholine [1]. In the so-called cholinergic anti-inflammatory pathway, enhanced efferent activity of parasympathetic nerve endings results in the release of acetylcholine, which, by a specific action on $\alpha 7$ nicotinic cholinergic receptors on macrophages, inhibits pro-inflammatory cytokine production [2]. Disruption of this pathway by surgical division of the vagus nerve led to enhanced release of tumour necrosis factor (TNF)- $\alpha$ and accelerated the development of hypotensive shock after i.v. injection of lipopolysaccharide (LPS) into rats [3]. Conversely, electrical stimulation of the efferent vagus nerve prevented the development of shock and attenuated the release of TNF- $\alpha$ in endotoxemic rats [3, 4]. Moreover, stimulation of $\alpha 7$ cholinergic receptors by specific agonists, such as nicotine or 3-(2,4-dimethoxybenzylidene) anabaseine (GTS-21), attenuated TNF- $\alpha$ release and improved survival in mice challenged with LPS [5-7] and in mice with abdominal sepsis induced by cecal ligation and puncture (CLP) $[6,7]$.
Recent evidence suggests that stimulation of $\alpha 7$ cholinergic receptors in the lung inhibits local inflammation. Alveolar macrophages and respiratory epithelial cells were reported to express $\alpha 7$ cholinergic receptors in the normal lung, whereas, in lungs with acid aspirationinduced injury, expression of $\alpha 7$ cholinergic receptors was also detected on infiltrating neutrophils [8]. In addition, systemic administration of nicotine, choline or the specific $\alpha 7$ agonist PNU-282987 attenuated acid aspiration-induced lung injury and inflammation, as reflected by a reduction in lung vascular permeability, neutrophil influx into bronchoalveolar lavage fluid (BALF) and local TNF- $\alpha$ concentrations [8]. Moreover, it was shown that intrapulmonary delivery of the $\alpha 7$ agonist GTS-21 attenuated TNF- $\alpha$ release into BALF of mice exposed to LPS via the airways [9]. To date, knowledge of the effect of cholinergic stimulation during lung infection is limited to one study, in which nicotine administration to mice was associated with enhanced viral loads during experimental influenza infection [10]. The current authors
AFFILIATIONS

${ }^{*}$ Center for Infection and Immunity Amsterdam (CINIMA),

${ }^{*}$ Center for Experimental and Molecular Medicine, and "Dept of Pathology, Academic Medical Center, University of Amsterdam, Amsterdam, The Netherlands.

\section{CORRESPONDENCE}

T. van der Poll

Academic Medical Center

Meibergdreef 9

Room G2-130

1105 AZ Amsterdam

The Netherlands

Fax: 31206977192

E-mail: t.vanderpoll@amc.uva.nl

Received:

July 072008

Accepted after revision:

September 192008

STATEMENT OF INTEREST

None declared. 
sought to determine the effect of nicotine on host defence against bacterial pneumonia. Such knowledge is important, considering that pneumonia has a considerable impact on healthcare and is the leading cause of sepsis [11, 12].

\section{MATERIALS AND METHODS}

\section{Mice}

Pathogen-free 9-week-old female C57BL/6 mice were purchased from Harlan (Horst, the Netherlands). The Institutional Animal Care and Use Committee of the Academic Medical Center (Amsterdam, the Netherlands) approved all experiments. At the start of the experiments, mice were 10 weeks old.

\section{Induction of pneumonia and design}

Pneumonia was induced as previously described [13-15]. Briefly, Streptococcus pneumoniae serotype 3 (ATCC 6303; American Type Culture Collection, Rockville, MD, USA) were grown for $6 \mathrm{~h}$ to mid-logarithmic phase at $37^{\circ} \mathrm{C}$ using ToddHewitt broth (Difco, Detroit, MI, USA), harvested by centrifugation at $1500 \times g$ for $10 \mathrm{~min}$ and washed twice in sterile isotonic saline. Bacteria were resuspended in sterile isotonic saline at a concentration of $1 \times 10^{6}$ colony-forming units $(\mathrm{CFU}) \cdot \mathrm{mL}^{-1}$, as determined by plating serial 10 -fold dilutions
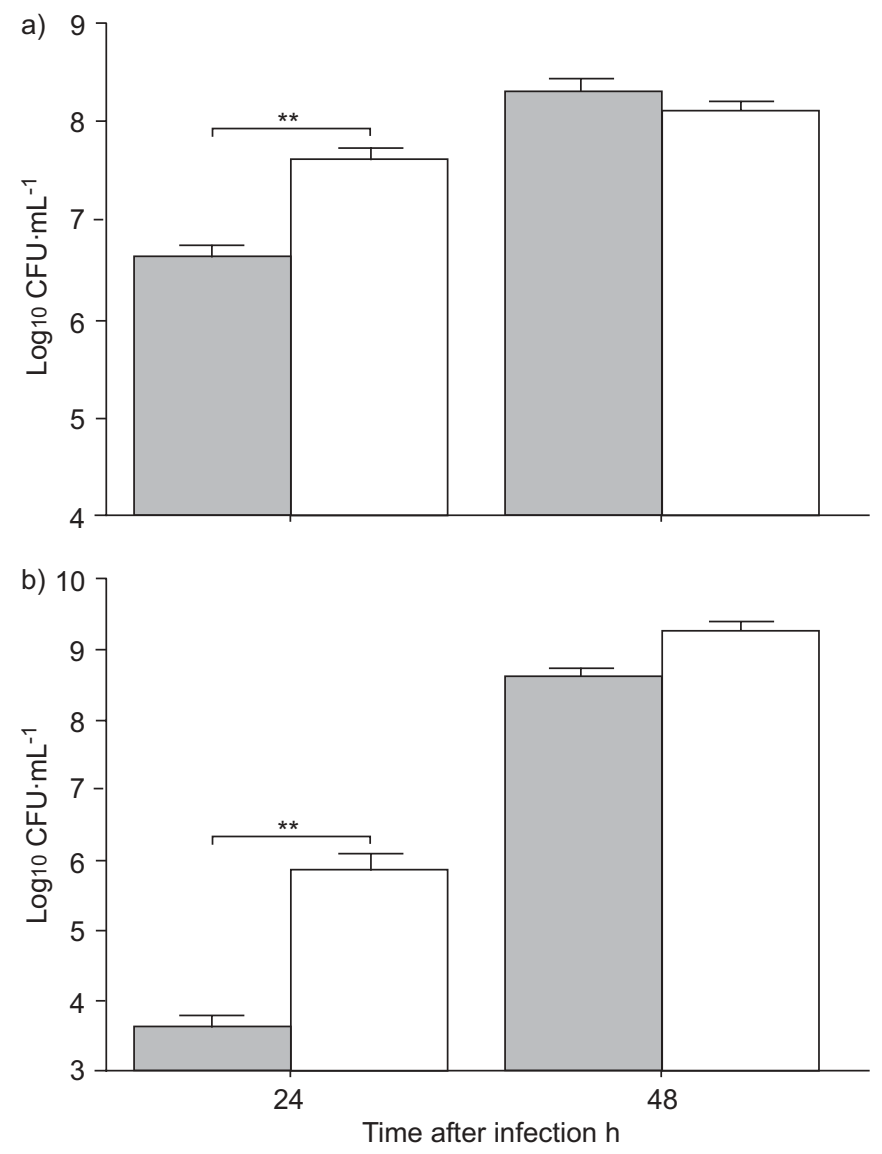

FIGURE 1. Nicotine treatment transiently enhanced bacterial outgrowth in a) lung and b) blood. Mice were intranasally infected with Streptococcus pneumoniae and treated with either nicotine $\left(400 \mu \mathrm{g} \cdot \mathrm{kg}^{-1} ; \square\right)$ or saline $(\square)$ every $8 \mathrm{~h}$ until sacrifice at 24 or $48 \mathrm{~h}$. Data represent mean \pm SEM of eight mice per group at each time-point. ${ }^{* *}: p<0.01$. on blood agar plates. After preparation of the inocula, mice were lightly anaesthetised by inhalation of $2 \%$ isoflurane (Abbott Laboratories Ltd, Queenborough, UK) in $2 \mathrm{~L}$ of $\mathrm{O}_{2}$, and $50 \mu \mathrm{L}$ of the bacterial suspension (containing $5 \times 10^{4} \mathrm{CFU}$ S. pneumoniae) was inoculated intranasally. Mice received an i.p. injection (total volume $200 \mu \mathrm{L}$ ) with either vehicle (sterile normal saline) or nicotine (Sigma-Aldrich Co., St Louis, MO, USA) at a dose of $400 \mu \mathrm{g} \cdot \mathrm{kg}^{-1}$ starting directly after infection and with 8-h intervals thereafter until the end of each experiment; this treatment schedule was previously shown to protect mice from death induced by either LPS or CLP-induced sepsis [7].

\section{Sample harvesting and preparation}

Mice were anaesthetised 4, 24 or $48 \mathrm{~h}$ after induction of pneumonia with Hypnorm ${ }^{\circledR}$ (Janssen Pharmaceutica, Beerse, Belgium; active ingredients fentanyl citrate and fluanisone) and midazolam (Roche, Meidrecht, the Netherlands) and sacrificed by bleeding out the vena cava inferior. Blood was collected in EDTA-containing tubes. Whole lungs were harvested and homogenised in four volumes of sterile saline using a tissue homogeniser (Biospec Products, Bartlesville, OK, USA). CFU numbers were determined in lungs and blood from serial dilutions plated on blood agar plates and incubated at $37^{\circ} \mathrm{C}$ for $16 \mathrm{~h}$ before colonies were counted. For cytokine measurements, lung homogenates were diluted with an equal volume of lysis buffer ( $\mathrm{pH} 7.4$ ) containing $300 \mathrm{mM} \mathrm{NaCl}$, $30 \mathrm{mM}$ Tris, $2 \mathrm{mM} \mathrm{MgCl} 2,2 \mathrm{mM} \mathrm{CaCl}, 1 \%$ Triton X-100, 4-(2aminoethyl)-benzenesulfonyl fluoride hydrochloride, EDTA, pepstatin A and leupeptin (all from MP Biomedicals, Solon, $\mathrm{OH}$, USA; concentrations in accordance with the manufacturer's recommendations) and incubated for $30 \mathrm{~min}$. Homogenates were centrifuged at $1500 \times g$ at $4{ }^{\circ} \mathrm{C}$ for $15 \mathrm{~min}$, and supernatants were stored at $-20^{\circ} \mathrm{C}$ until assays were performed.

\section{Histology}

Lungs for histology were prepared and analysed by a pathologist (S. Florquin) who was blinded with respect to treatment groups, as previously described [13-15]. The parameters bronchitis, oedema, interstitial inflammation, intraalveolar inflammation, pleuritis and endothelialitis were graded on a scale of 0 to 4 , with 0 as "absent" and 4 as "severe". The total "lung inflammation score" was expressed as the sum of the scores for each parameter, the maximum being 24 . Additionally, the percentage of inflammation was determined. Granulocyte staining was performed using fluorescein isothiocyanate-labelled rat anti-mouse Ly-6G monoclonal antibody (mAb; Pharmingen, San Diego, CA, USA) exactly as previously described [14].

\section{Assays}

TNF- $\alpha$, interleukin (IL)- 6 , interferon (IFN)- $\gamma$, IL-10 and monocyte chemoattractant protein (MCP)-1 levels were determined using a commercially available cytometric beads array multiplex assay (BD Biosciences, San Jose, CA, USA) in accordance with the manufacturer's recommendations. Macrophage inflammatory protein (MIP)-2 and keratinocyte chemoattractant $(\mathrm{KC})$ were measured by ELISA (R\&D Systems, Abingdon, $\mathrm{UK})$. 

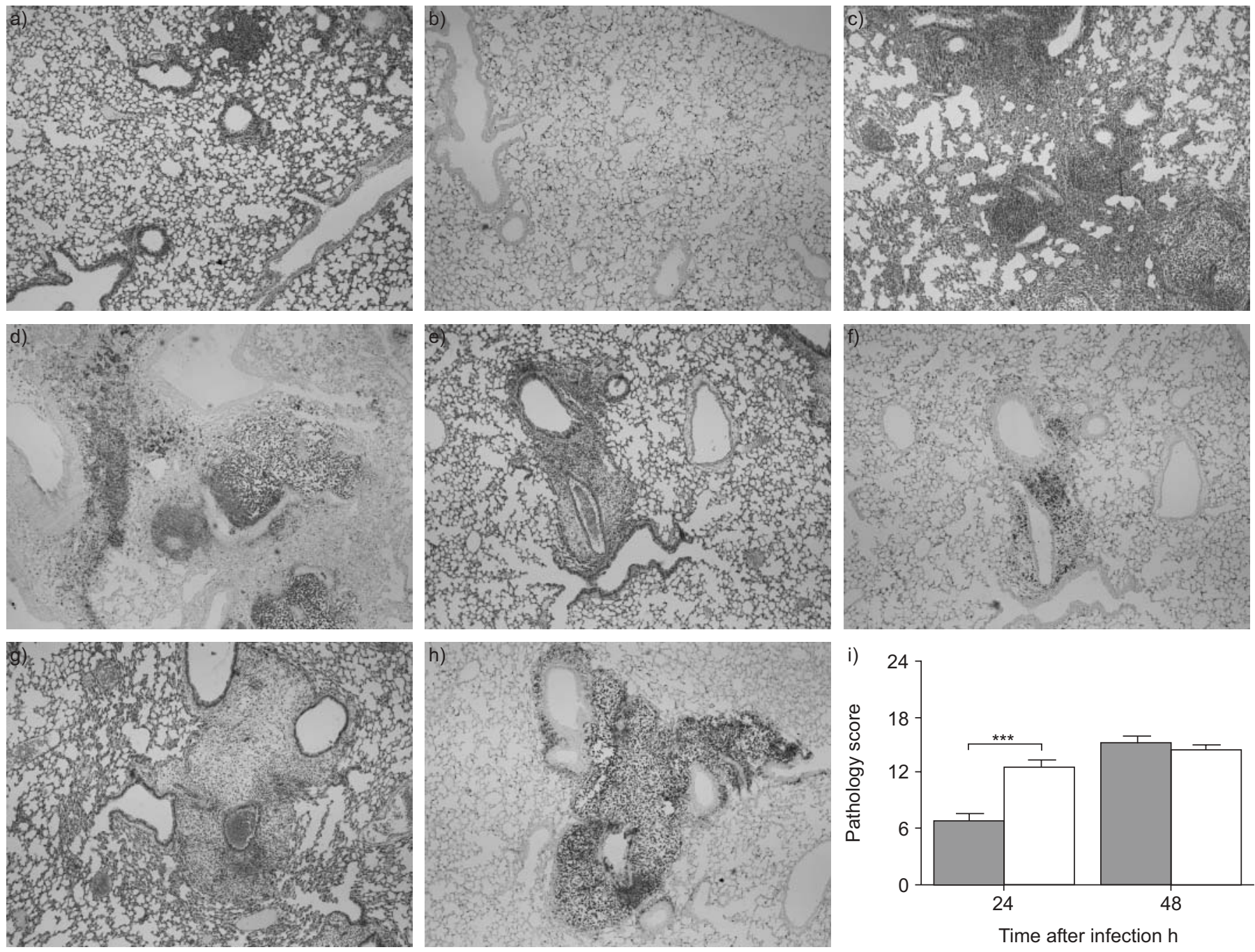

FIGURE 2. Nicotine transiently enhanced pneumonia-induced lung pathology. Mice were intranasally infected with Streptococcus pneumoniae and treated with either nicotine $\left(400 \mu \mathrm{g} \cdot \mathrm{kg}^{-1}\right)$ or saline every $8 \mathrm{~h}$ until sacrifice at 24 or $48 \mathrm{~h}$. Representative lung slides of saline-treated (a-d) and nicotine-treated (e-h) mice $24 \mathrm{~h}(\mathrm{a}, \mathrm{b}, \mathrm{e}$ and f) and $48 \mathrm{~h}(\mathrm{c}, \mathrm{d}, \mathrm{g}$ and $\mathrm{h}$ ) after infection. Haematoxylin and eosin staining ( $\mathrm{a}, \mathrm{c}, \mathrm{e}$ and $\mathrm{g})$ and $\mathrm{Ly}-6 \mathrm{G}$ granulocyte staining (b, $\mathrm{d}, \mathrm{f}$ and $\mathrm{h}$ ) were performed. All pictures were taken at $4 \times$ magnification and are representative for eight mice per group at each time-point. i) Semiquantitative pathology scores (determined by a scoring system as described in the Methods section), 24 and $48 \mathrm{~h}$ after infection. Data represent mean \pm SEM of eight mice per group at each time-point. $\square^{-}$: saline-treated mice; $\square$ : nicotine-treated mice.

$* * *: p<0.001$

\section{Statistical analysis}

All values are presented as mean \pm SEM. Differences between groups were analysed by Mann-Whitney U-tests. Correlations between bacterial loads and lung cytokine concentrations were calculated using the Spearman rho test. Values of $p<0.05$ were considered to be statistically significant.

\section{RESULTS}

\section{Nicotine transiently impairs antibacterial defence}

To obtain a first insight into the impact of nicotine on host defence during pneumonia, mice were infected with S. pneumoniae and concurrently treated with either nicotine $\left(400 \mu \mathrm{g} \cdot \mathrm{kg}^{-1}\right)$ or normal saline every $8 \mathrm{~h}$ [7]. In the first experiments, mice were killed 24 or $48 \mathrm{~h}$ after infection and bacterial loads were determined in whole lungs and blood (fig. 1). Nicotine treatment was associated with significantly higher bacterial burdens in both lungs and blood at $24 \mathrm{~h}$ post-infection (both $\mathrm{p}<0.01$ versus saline). Bacterial loads increased in both treatment groups thereafter and no differences existed at $48 \mathrm{~h}$ (fig. 1).

\section{Impact of nicotine on lung inflammation}

Nicotine and other $\alpha 7$ cholinergic agonists have been reported to exert anti-inflammatory effects in models of sterile lung injury $[8,9]$. In theory such anti-inflammatory effects could impair antibacterial defence, considering that a certain extent of inflammation is required for an adequate innate immune response to respiratory pathogens $[16,17]$. Therefore, the effect of nicotine on the pulmonary inflammation accompanying pneumonia was determined by semiquantitative analysis of lung histopathology (fig. 2). Nicotine treatment was associated with increased lung inflammation at $24 \mathrm{~h}$ after induction of pneumonia, as reflected by an increased pathology score at this time-point ( $\mathrm{p}<0.001$ versus saline). The enhanced inflammatory response in nicotine-treated animals was further illustrated by 

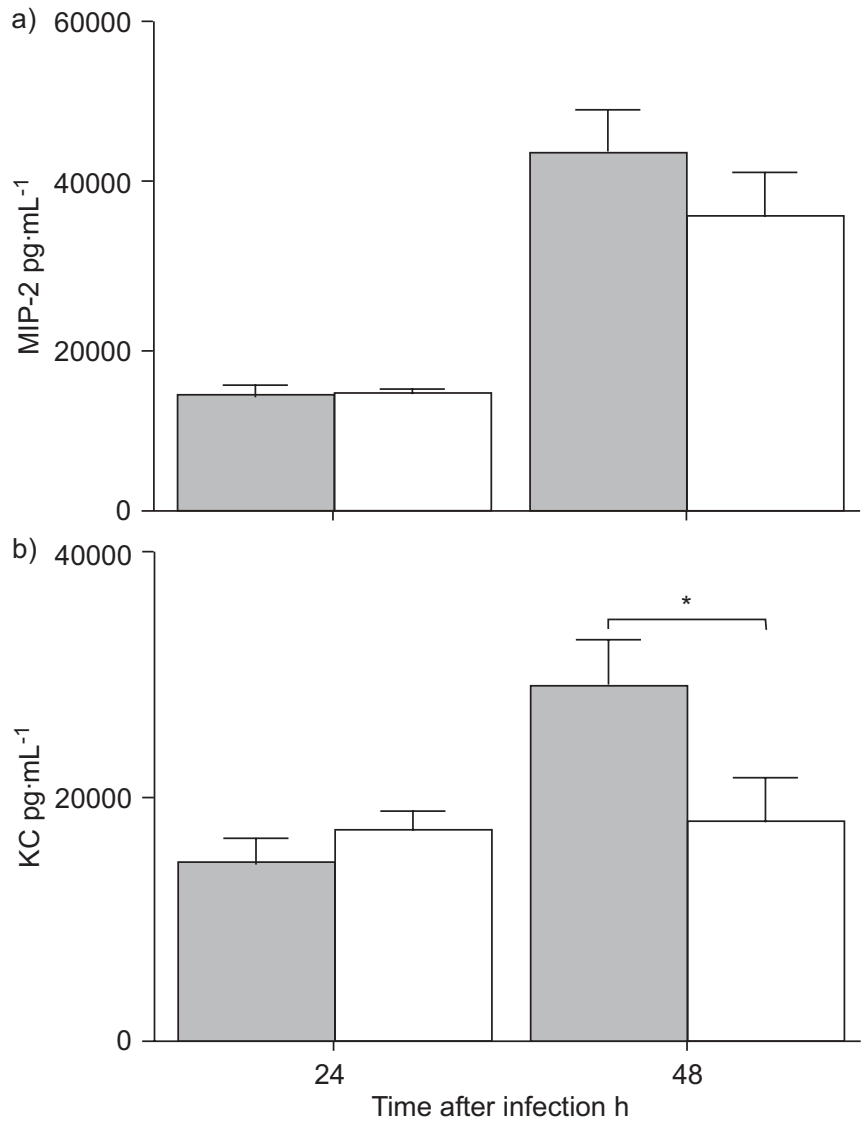

FIGURE 3. Lung chemokine levels. Mice were intranasally infected with Streptococcus pneumoniae and treated with either nicotine $\left(400 \mu \mathrm{g} \cdot \mathrm{kg}^{-1} ; \square\right)$ or saline ( $\square$ ) every $8 \mathrm{~h}$ until sacrifice at 24 or $48 \mathrm{~h}$. a) Macrophage inflammatory protein (MIP)-2 and b) keratinocyte chemoattractant (KC) levels were measured by ELISA. Data represent mean \pm SEM of eight mice per group at each time-point. * $p<0.05$.

a strongly increased neutrophil recruitment into lung tissue, as shown by Ly-6G staining for neutrophils (fig. $2 b$ and $d$ ). At $48 \mathrm{~h}$ after infection, pathology scores no longer differed between groups. Since CXC chemokines have been implicated in the recruitment of neutrophils to sites of inflammation [18], the local concentrations of MIP-2 and KC were determined in whole lung homogenates. Nicotine did not influence pulmonary MIP-2 or KC levels at $24 \mathrm{~h}$ after infection. At $48 \mathrm{~h}, \mathrm{KC}$ levels were lower in nicotine-treated mice $(\mathrm{p}<0.05$ versus saline), whereas MIP-2 levels were similar in both groups (fig. 3).

\section{Nicotine increases lung and plasma cytokine levels}

To obtain a further insight into the effect of nicotine on the host inflammatory response during pneumococcal pneumonia, local and systemic cytokine concentrations were measured at 24 and $48 \mathrm{~h}$ after infection (fig. 4). Nicotine treatment was associated with higher lung levels of TNF- $\alpha$ and IFN- $\gamma$, and higher plasma levels of TNF- $\alpha$, IFN- $\gamma$ and MCP-1 at $24 \mathrm{~h}$ after infection (all $\mathrm{p}<0.05$ versus saline). At $48 \mathrm{~h}$, neither lung nor plasma concentrations of these mediators differed between groups. The pulmonary and plasma levels of IL-6 and IL-10 were similar in both groups at both time-points. To evaluate whether lung cytokine levels were proportionate to the bacterial load, the correlations between pulmonary bacterial loads and cytokine levels $24 \mathrm{~h}$ after infection were calculated. Positive correlations were found between bacterial load and TNF- $\alpha(\mathrm{r}=0.71, \mathrm{p}<0.005)$, IL-6 $(\mathrm{r}=0.63, \mathrm{p}<0.01)$ and IFN- $\gamma$ $(\mathrm{r}=0.74, \mathrm{p}=0.001)$; correlations between bacterial loads and MCP-1 or IL-10 levels were not significant.

\section{Impact of nicotine on the early immune response}

The enhanced cytokine response at $24 \mathrm{~h}$ post-infection in nicotine-treated mice could have been the result of the higher bacterial loads in these animals, providing a more potent proinflammatory stimulus. Therefore, the current authors wished to evaluate the influence of nicotine on the early inflammatory response to pneumonia. Mice were intranasally infected with S. pneumoniae, treated immediately thereafter with either nicotine $\left(400 \mu \mathrm{g} \cdot \mathrm{kg}^{-1}\right)$ or saline, and lungs and blood were obtained $4 \mathrm{~h}$ later. At this early time-point, bacterial loads in lungs did not differ between groups (table 1), whereas blood cultures remained sterile (data not shown). Lung concentrations of cytokines and chemokines did not differ between groups, with the exception of IL-6 levels, which were higher in nicotine-treated animals ( $\mathrm{p}<0.05$ versus saline; table 1 ). Please note that overall cytokine levels were low in both groups. IFN- $\gamma$ levels were below detection level. Plasma cytokine levels were either very low or undetectable in both nicotine- and saline-treated animals and not different between groups (data not shown).

\section{DISCUSSION}

The cholinergic anti-inflammatory pathway, mediated by the vagus nerve and $\alpha 7$ cholinergic receptors, has been implicated as a neuronal feedback system that serves to limit inflammatory responses [1]. It has recently been demonstrated that chemical stimulation of $\alpha 7$ cholinergic receptors in the pulmonary compartment results in inhibition of sterile lung inflammation induced by local instillation of either LPS or acid $[8,9]$. The current authors sought to determine the effect of nicotine on the host response to respiratory tract infection caused by the most common causative pathogen in community-acquired pneumonia, S. pneumoniae. The main finding was that nicotine transiently impairs host defence during pneumococcal pneumonia as reflected by higher bacterial loads in lungs and blood in mice treated with nicotine, $24 \mathrm{~h}$ after induction of pneumonia. The enhanced growth of pneumococci was accompanied by increased inflammation in the lungs, as indicated by histopathology and cytokine levels.

Several lines of evidence indicate that stimulation of the vagus nerve and/or pharmacological $\alpha 7$ cholinergic receptor agonists may be a useful strategy in the treatment of the severe inflammation accompanying sepsis. First, electrical stimulation of the efferent vagus nerve prevented the development of shock and attenuated the release of TNF- $\alpha$ in endotoxemic rats $[3,4]$. Secondly, both electrical stimulation of the vagus nerve and stimulation of $\alpha 7$ cholinergic receptors by specific agonists diminished systemic inflammation and improved the outcome of mice with polymicrobial abdominal sepsis $[6,7,19]$. Thus far, knowledge of the impact of stimulation of $\alpha 7$ cholinergic receptors in pneumonia has been highly limited. In light of the 

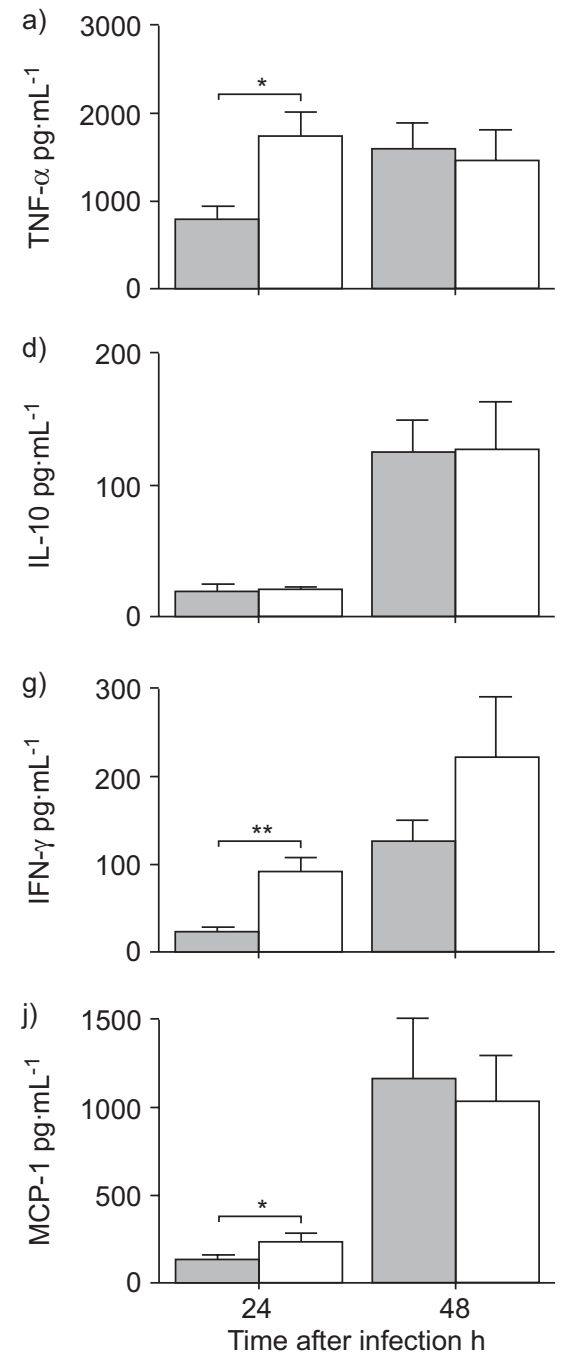
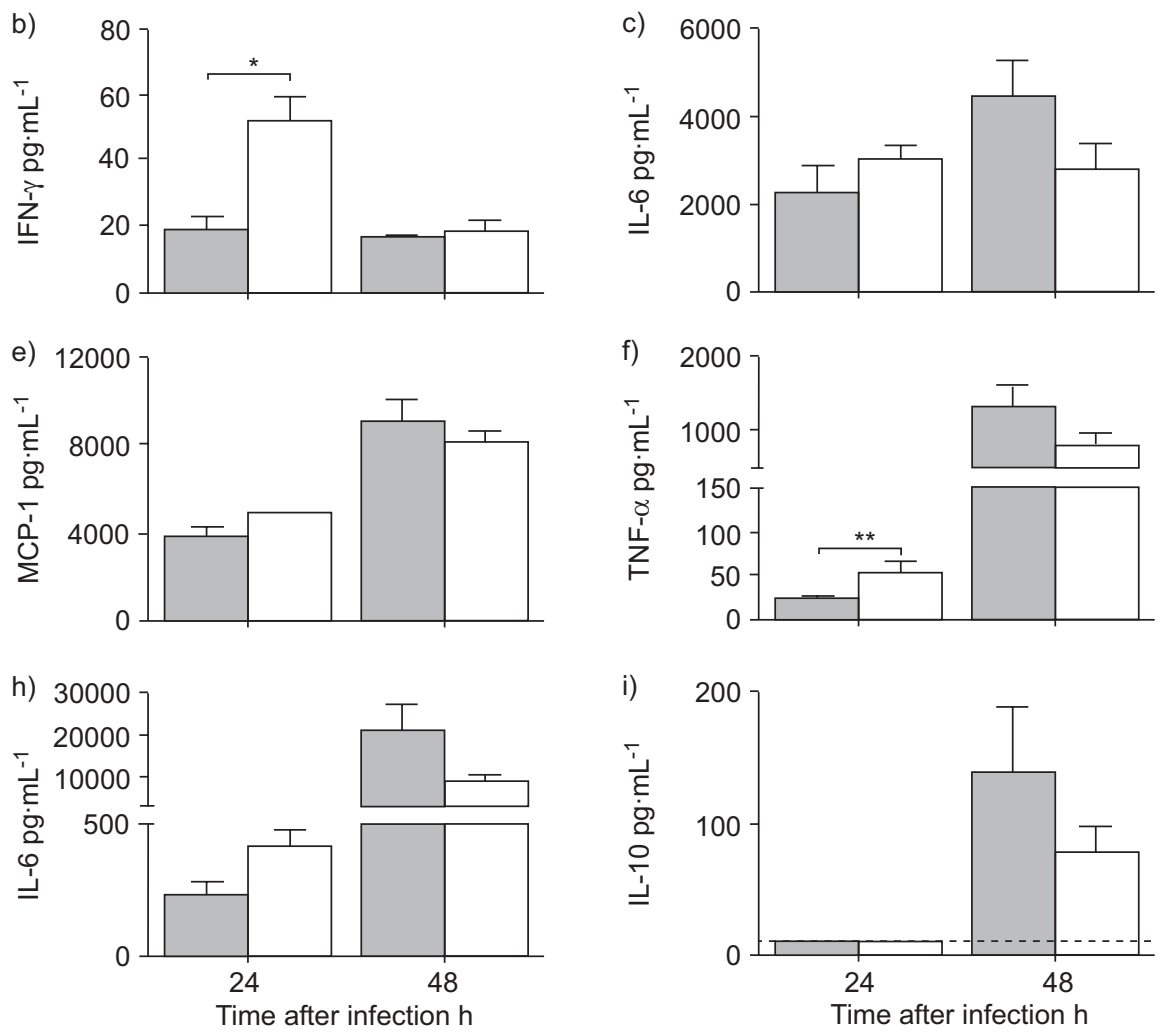

FIGURE 4. Lung (a-e) and plasma (f-j) levels of tumour necrosis factor (TNF)- $\alpha$ (a and f), interferon (IFN)- $\gamma$ (b and g), interleukin (IL)-6 (c and h), IL-10 (d and i) and monocyte chemoattractant protein (MCP)-1 (e and j). Mice were intranasally infected with Streptococcus pneumoniae and treated with either nicotine $\left(400 \mu \mathrm{g} \cdot \mathrm{kg}^{-1} ; \square\right)$ or saline $(\square)$ every $8 \mathrm{~h}$ until sacrifice at 24 or $48 \mathrm{~h}$. Data represent mean \pm SEM of eight mice per group at each time-point. - - - - detection limit. ${ }^{*}: p<0.05$; ${ }^{\star *}: p<0.01$.

TABLE 1 Effect of nicotine on the very early (4-h) lung host response to pneumococcal pneumonia

\begin{tabular}{lcc} 
Measurements & Saline & Nicotine \\
\hline Bacterial load $\log _{10} \mathrm{CFU} \cdot \mathrm{mL}^{-1}$ & $4.03 \pm 0.09$ & $4.14 \pm 0.07$ \\
Cytokines/chemokines $\mathbf{~ p g} \cdot \mathbf{m L}^{-1}$ & & \\
$\quad$ MIP-2 & $9842 \pm 702$ & $11460 \pm 907$ \\
KC & $4023 \pm 46$ & $4426 \pm 680$ \\
TNF- $\alpha$ & $67.4 \pm 7.5$ & $63.0 \pm 8.3$ \\
IL-6 & $18.0 \pm 2.3$ & $30.2 \pm 3.7^{\star}$ \\
IL-10 & $26.6 \pm 5.6$ & $14.4 \pm 2.4$ \\
MCP-1 & $455 \pm 69$ & $426 \pm 101$ \\
\hline
\end{tabular}

Mice were intranasally infected with Streptococcus pneumoniae and treated with either nicotine $\left(400 \mu \mathrm{g} \cdot \mathrm{kg}^{-1}\right)$ or saline directly after infection. Mice were killed $4 \mathrm{~h}$ later. Data represent mean \pm SEM of eight mice per group at each timepoint. CFU: colony-forming units; MIP: macrophage inflammatory protein; KC: keratinocyte chemoattractant; TNF: tumour necrosis factor; IL: interferon; MCP: monocyte chemoattractant protein. ${ }^{*}: p<0.05$ versus saline. fact that pneumonia is the most common cause of sepsis [11], such knowledge is of great relevance for further exploration of manipulation of the cholinergic anti-inflammatory pathway as a potential novel therapeutic strategy in sepsis. In this respect, pneumonia caused by $S$. pneumoniae is especially important. $S$. pneumoniae is the most prevalent micro-organism in community-acquired pneumonia, responsible for more than half a million cases each year in the USA alone, bearing a fatality rate of $5-7 \%$ [20]. Bacteraemia with S. pneumoniae originates, in almost $90 \%$ of cases, from the lungs. In addition, in recent sepsis trials, the pneumococcus was an important causative pathogen, especially in the context of pneumonia [21].

Recent studies have shown that $\alpha 7$ cholinergic receptors are expressed in the lung and that stimulation of these receptors by various treatments attenuates lung inflammation and injury $[8,9]$. In one of these investigations nicotine, given as a single dose of $3.5 \mathrm{mg} \cdot \mathrm{kg}^{-1}$, was shown to reduce pulmonary oedema, lung vascular permeability, neutrophil infiltration and TNF- $\alpha$ and MIP-2 release, via an $\alpha 7$ cholinergic receptor-dependent mechanism in a model of acid aspiration-induced pneumonitis [8]. In contrast to the model of acid aspiration-induced lung 
injury, which induces acute lung inflammation, experimentally induced pneumococcal pneumonia is associated with a gradual onset of inflammation and the development of an innate immune response over the first 24-48 h [13-15]. Hence, rather than giving a single high dose, the current authors chose a nicotine dosing and treatment scheme that previously was demonstrated to reduce lethality and systemic inflammation induced by abdominal sepsis-caused CLP-induced faecal peritonitis $\left(400 \mu \mathrm{g} \cdot \mathrm{kg}^{-1}\right.$ every $\left.8 \mathrm{~h}\right)$ [7]. This dose is in the same range as used in a model of influenza pneumonia, when nicotine, administered by mini-osmotic pumps at a rate of 1$2 \mathrm{mg} \cdot \mathrm{kg}^{-1} \cdot \mathrm{day}^{-1}$, reduced lung inflammation as measured by histopathology [10]. Moreover, a nicotine dose within the same range was reported to be effective in reducing LPS-induced systemic inflammation [7], LPS-induced uveitis [22] and renal ischaemia/reperfusion injury [23]. Together, these data indicate that nicotine, while effective in diminishing systemic and lung inflammation in several models, is not effective in reducing lung inflammation in the clinically relevant model of pneumococcal pneumonia. The apparent discrepancy between the current study and earlier studies on the effects of nicotine may not only be related to the differences in body compartments examined (lung versus abdominal cavity/ circulation), but also to the type of causing micro-organism (Gram-positive versus Gram-negative). In this respect it would be interesting to study the effect of nicotine during Gramnegative pneumonia. It is of note that, at $24 \mathrm{~h}$ after infection, most parameters of inflammation (histopathology and cytokine concentrations) were exaggerated in mice treated with nicotine. This was most likely caused by the relatively increased bacterial loads (providing a more potent proinflammatory stimulus) at this time-point. Indeed, this "proinflammatory" effect of nicotine was only seen at the timepoint where bacterial loads were higher $(24 \mathrm{~h})$ and not at either an earlier $(4 \mathrm{~h})$ or later $(48 \mathrm{~h})$ time-point; in addition, the extent of inflammation in this model closely follows the bacterial burden in the lungs [17, 24], and strong correlations were found between the pulmonary bacterial load and pro-inflammatory cytokine concentrations in the current study. This may also explain why at $24 \mathrm{~h}$ more neutrophils were present in the lungs of mice treated with nicotine. In this respect, it should be noted that neutrophils express several nicotinic receptors, including the $\alpha 7$ cholinergic receptor [25], and that stimulation of these receptors has been shown to inhibit rather than enhance neutrophil migration [26].

As mentioned, nicotine treatment was associated with higher bacterial loads at $24 \mathrm{~h}$ after infection. Considering that an adequate early inflammatory reaction in the lung is essential for mounting an effective host defence response in this model of pneumococcal pneumonia [17], it was speculated that nicotine might inhibit the innate immune response very early after infection and thereby facilitate subsequent bacterial growth. However, such an effect of nicotine could not be shown at $4 \mathrm{~h}$ after infection with $S$. pneumoniae (table 1). An alternative explanation could be a relatively defective phagocytosis and/or killing of S. pneumoniae in the presence of nicotine. Indeed, nicotine has been reported to enhance the replication of Legionella pneumophila in cultures of mouse alveolar macrophages, which was associated with inhibition of the production of pro-inflammatory cytokines such as TNF- $\alpha$ and IL-12 [27]. Moreover, exposure of human neutrophils to nicotine reduced their ability to kill several oral bacterial pathogens [28]. Ongoing current studies are examining in detail the effect of various cholinergic receptor agonists on antibacterial effector functions of different leukocyte subsets.

Although the present study did not examine the effect of inhaled nicotine during pneumococcal pneumonia, it is interesting to note that smokers and even nonsmokers exposed to second-hand smoke have an increased risk for invasive pneumococcal infection [29]. A causative role for smoking in the pathogenesis of pneumococcal pneumonia is plausible, but has not been directly demonstrated. Clearly, smoking damages local immune defences within the airways and can enhance the binding of S. pneumoniae to pharyngeal cells [30]. The current study has added to this that parenteral nicotine exposure transiently facilitates the growth of pneumococci in the lungs of mice experimentally infected with this pathogen.

In conclusion, the present study showed that nicotine, given at a dose and treatment schedule that was earlier found to protect mice from death due to cecal ligation and puncture-induced polymicrobial sepsis [7], transiently impairs antibacterial defence during pneumococcal pneumonia. Nicotine was unable to inhibit the inflammatory response to Streptococcus pneumoniae in the lung or the circulation: one day after infection, when bacterial loads were increased in nicotinetreated mice, pulmonary and systemic inflammation were even enhanced.

\section{ACKNOWLEDGEMENTS}

The authors would like to thank J. Daalhuisen and M. ten Brink (both Academic Medical Center, University of Amsterdam, Amsterdam, the Netherlands) for excellent technical assistance.

\section{REFERENCES}

1 Tracey KJ. Physiology and immunology of the cholinergic antiinflammatory pathway. J Clin Invest 2007; 117: 289-296.

2 Wang H, Yu M, Ochani M, et al. Nicotinic acetylcholine receptor $\alpha 7$ subunit is an essential regulator of inflammation. Nature 2003; 421: 384-388.

3 Borovikova LV, Ivanova S, Zhang M, et al. Vagus nerve stimulation attenuates the systemic inflammatory response to endotoxin. Nature 2000; 405: 458-462.

4 van Westerloo DJ, Giebelen IA, Meijers JC, et al. Vagus nerve stimulation inhibits activation of coagulation and fibrinolysis during endotoxemia in rats. J Thromb Haemost 2006; 4: 1997-2002.

5 Giebelen IA, van Westerloo DJ, LaRosa GJ, de Vos AF, van der Poll T. Stimulation of $\alpha 7$ cholinergic receptors inhibits lipopolysaccharide-induced neutrophil recruitment by a tumor necrosis factor- $\alpha$-independent mechanism. Shock 2007; 27: 443-447.

6 Pavlov VA, Ochani M, Yang LH, et al. Selective $\alpha 7$-nicotinic acetylcholine receptor agonist GTS-21 improves survival in murine endotoxemia and severe sepsis. Crit Care Med 2007; 35: 1139-1144.

7 Wang $\mathrm{H}$, Liao $\mathrm{H}$, Ochani $\mathrm{M}$, et al. Cholinergic agonists inhibit HMGB1 release and improve survival in experimental sepsis. Nat Med 2004; 10: 1216-1221. 
$8 \mathrm{Su}$ X, Lee JW, Matthay ZA, et al. Activation of the $\alpha 7$ $\mathrm{nAChR}$ reduces acid-induced acute lung injury in mice and rats. Am J Respir Cell Mol Biol 2007; 37: 186-192.

9 Giebelen IA, van Westerloo DJ, LaRosa GJ, de Vos AF, van der Poll T. Local stimulation of $\alpha 7$ cholinergic receptors inhibits LPS-induced TNF- $\alpha$ release in the mouse lung. Shock 2007; 28: 700-703.

10 Razani-Boroujerdi S, Singh SP, Knall C, et al. Chronic nicotine inhibits inflammation and promotes influenza infection. Cell Immunol 2004; 230: 1-9.

11 Annane D, Bellissant E, Cavaillon JM. Septic shock. Lancet 2005; 365: 63-78.

12 Mandell LA. Epidemiology and etiology of communityacquired pneumonia. Infect Dis Clin North Am 2004; 18: 761-776.

13 Dessing MC, Knapp S, Florquin S, de Vos AF, van der Poll T. CD14 facilitates invasive respiratory tract infection by Streptococcus pneumoniae. Am J Respir Crit Care Med 2007; 175: 604-611.

14 Knapp S, Wieland CW, van 't Veer C, et al. Toll-like receptor 2 plays a role in the early inflammatory response to murine pneumococcal pneumonia but does not contribute to antibacterial defense. J Immunol 2004; 172: 3132-3138.

15 Rijneveld AW, Weijer S, Florquin S, et al. Thrombomodulin mutant mice with a strongly reduced capacity to generate activated protein $C$ have an unaltered pulmonary immune response to respiratory pathogens and lipopolysaccharide. Blood 2004; 103: 1702-1709.

16 Strieter RM, Belperio JA, Keane MP. Cytokines in innate host defense in the lung. J Clin Invest 2002; 109: 699-705.

17 Knapp S, Schultz MJ, van der Poll T. Pneumonia models and innate immunity to respiratory bacterial pathogens. Shock 2005; 24: Suppl. 1, 12-18.

18 Olson TS, Ley K. Chemokines and chemokine receptors in leukocyte trafficking. Am J Physiol Regul Integr Comp Physiol 2002; 283: R7-R28.

19 Huston JM, Gallowitsch-Puerta M, Ochani M, et al. Transcutaneous vagus nerve stimulation reduces serum high mobility group box 1 levels and improves survival in murine sepsis. Crit Care Med 2007; 35: 2762-2768.
20 Campbell GD Jr. Commentary on the 1993 American Thoracic Society guidelines for the treatment of community-acquired pneumonia. Chest 1999; 115: Suppl. 3, 14S-18S.

21 Opal SM, Garber GE, LaRosa SP, et al. Systemic host responses in severe sepsis analyzed by causative microorganism and treatment effects of drotrecogin $\alpha$ (activated). Clin Infect Dis 2003; 37: 50-58.

22 Chi ZL, Hayasaka S, Zhang XY, Cui HS, Hayasaka Y. A cholinergic agonist attenuates endotoxin-induced uveitis in rats. Invest Ophthalmol Vis Sci 2007; 48: 2719-2725.

23 Sadis C, Teske G, Stokman G, et al. Nicotine protects kidney from renal ischemia/reperfusion injury through the cholinergic anti-inflammatory pathway. PLoS ONE 2007; 2: e469.

24 Bergeron Y, Ouellet N, Deslauriers AM, Simard M, Olivier M, Bergeron MG. Cytokine kinetics and other host factors in response to pneumococcal pulmonary infection in mice. Infect Immun 1998; 66: 912-922.

25 Cormier A, Paas Y, Zini R, et al. Long-term exposure to nicotine modulates the level and activity of acetylcholine receptors in white blood cells of smokers and model mice. Mol Pharmacol 2004; 66: 1712-1718.

26 Speer P, Zhang Y, Gu Y, Lucas MJ, Wang Y. Effects of nicotine on intercellular adhesion molecule expression in endothelial cells and integrin expression in neutrophils in vitro. Am J Obstet Gynecol 2002; 186: 551-556.

27 Matsunaga K, Klein TW, Friedman H, Yamamoto Y. Involvement of nicotinic acetylcholine receptors in suppression of antimicrobial activity and cytokine responses of alveolar macrophages to Legionella pneumophila infection by nicotine. J Immunol 2001; 167: 6518-6524.

28 Pabst MJ, Pabst KM, Collier JA, et al. Inhibition of neutrophil and monocyte defensive functions by nicotine. J Periodontol 1995; 66: 1047-1055.

29 Nuorti JP, Butler JC, Farley MM, et al. Cigarette smoking and invasive pneumococcal disease. Active Bacterial Core Surveillance Team. N Engl J Med 2000; 342: 681-689.

30 Sheffield JV, Root RK. Smoking and pneumococcal infection. $N$ Engl J Med 2000; 342: 732-734. 